\title{
The Bender Gestalt-II an Underutilized Tool in Brief Neurological Screening
}

\author{
Michael F Shaughnessy* \\ Department of Neurology, USA
}

*Corresponding author: Michael F Shaughnessy, Department of Neurology, USA.

Received Date: October 23, 2018

Published Date: December 03, 2018

\begin{abstract}
School personnel and others involved with students with head injury, brain damage and concussion have difficulty monitoring recovery and progress of therapeutic intervention in cases of children and adolescents who have suffered a head trauma. The recently revised Bender Gestalt II is a quick, and reliable dependable test that will at least provide some information as to recovery from head injury or concussion and will provide a way in which clinicians can monitor progress and recovery. This article will provide preliminary information about the revised Bender Gestalt II and outline some ways in which this instrument can be employed to provide feedback as to growth and recovery regarding head injury.
\end{abstract}

Keywords: Neurological; Bender Gestalt II; Screening and evaluation

\section{Introduction}

Sadly, often infants, children, and even adolescents suffer some form or type of head injury-be it open head injury or closed head injury or some type of concussion which in general resolves itself fairly quickly. School and other personnel, however are faced with the predicament of monitoring the recovery of said patients and students that may have been hospitalized due to a head injury or trauma. It is imperative that said students receive some type of assistance and intervention, and in some cases, cognitive rehabilitation and it is even more imperative that students be monitored post injury to ascertain progress and growth. The recently revised Bender Gestalt-II is an excellent screening tool for monitoring at least the visual motor and perceptual skills of students with a head injury. The original Bender Gestalt test has been a well-accepted instrument for many years and has enjoyed many decades of books and different scoring systems that help to document development, and visual motor perceptual skills. Many books have been written about the Bender and its various scoring systems and the original Bender Gestalt has been widely accepted. The recently revised Bender Gestalt II has added a few cards to supplement the original Bender and these cards have added more "floor and ceiling" and have provided a new manual describing the changes in the Bender-Gestalt II, the scoring system, and the ways in which it can be employed with various groups.
The recently revised Bender Gestalt II has an observation form which includes a) physical observations, b) test taking observations c) copy observations d) a section for recall and a summary section for documenting the age of the student, date of testing and date of birth as well as any other supplemental tests that may have been administered (motor, perception). Standard scores, percentile ranks, and $\mathrm{T}$ scores can be indicated on these forms. There are two additional parts to the Bender -Gestalt- the Motor test which presents challenges to some subjects in terms of connecting dots of increasingly difficult complexity, as well as a supplementary Perception test, which asks the subject to identify a figure shown on the left-hand side with those 4 on the right hand side-as an example. If the letter $\mathrm{X}$ was shown on the left hand side- the subject would be presented with four distractors such as Z-Q-M X and the subject would be asked to circle or indicate the similar figure on the right. Certainly, this is a type of visual discrimination, and examiners should make sure that the student or subject is wearing their prescriptive lenses.

The Bender Gestalt II "is comprised of 16 designs, broken into two separate tests: 13 designs (original 9 and 4 easier) for individuals below age 8 and 12 designs (original 9 and 3 more difficult) for individuals 8 and older" [1]. Brannigan et al. [2] have a small manual on the new innovative features of the revised Bender 
Gestalt-II and have provided expanded guidelines for the use of the Global Scoring System.

\section{Review of the Literature}

Piotrowski [3] has provided the most comprehensive review and analysis of the use of the original Bender and this article is the most recent with the most relevant information Shaughnessy \& Laman [4] have written on the need for evidence-based intervention in the treatment and rehabilitation of traumatic brain injury. Shaughnessy [5] has written on the use of the Bender Gestalt II in conjunction with the Wechsler scales to provide a more indepth comprehensive overview of the student's present level of performance and functioning. Brannigan \& Decker [6] have worked extensively to provide an up to date manual of the Bender Gestalt II. Brannigan, \& Decker [7] are the authors responsible for the revision of the Bender Visual Motor Gestalt Test- Second Edition and a comprehensive review of the revision procedures were provided in Brannigan \& Decker [1] explaining the revision and uses of the Bender Gestalt II. This article published in the American Journal of Orthopsychiatry was seen as a global overview of the uses of the new Bender Gestalt. Brannigan \& Shaughnessy [8] discussed the various use of the Bender and the entire process of revising the Bender-Gestalt II in the North American Journal of Psychology. Volker and his associates [9] have employed the Bender Gestalt II and compared it to the use of the VMI with children on the autism spectrum.

The Use of the Bender-Gestalt II in terms of Monitoring Growth and Recovery. Since the Bender Gestalt II can be very quickly administered, simply using an 8- and one-half sheet of paper and a number two lead pencil, it can be easily administered and scored using the revised manual. It would probably be appropriate for the Bender to be administered at least on a yearly basis- perhaps in conjunction with a gross motor or other skill (fine or gross motor) to ascertain developmental readiness for more difficult academic tasks. Often teachers seem to forget that as the student progresses from grade to grade, subject to subject that the academic work does require more concentration, focus and attention. While the Bender Gestalt II does not specifically address all of the above domains, at least there is some objective measure of the student's progress, in lieu of an academic achievement test or an individually administered cognitive measure.

Since standard scores are employed the results can be quickly ascertained in terms of improvement. Decker [10] has discussed the measurement of both growth and decline in visual motor processes with the second edition of the Bender Gestalt. Since there are two forms of the Bender Gestalt -II (one for younger children and another for older), clinicians must be astutely aware of these differences. In the schools, when clinicians are concerned about recovery from head injury, or brain damage, or trauma, the Bender Gestalt II can provide on-going information about visual motor processing, visual memory and visual discrimination $[11,12]$.

\section{Conclusion}

This paper has cursorily reviewed the use of the newly revised Bender Gestalt II in the monitoring and recovery of individuals who have sustained a head injury or insult to the brain. Some of the relevant literature has been reviewed and suggestions for future research have been delineated. In this age of evidencebased investigation, it is imperative to have data that is available to document progression terms of intervention and recovery. The Bender Gestalt- II is one alternative to a full neurological examination, which may not always be available to involved clinicians.

\section{Acknowledgement}

None

\section{Conflict of Interest}

No conflict of interest.

\section{References}

1. Brannigan GG, Decker SL (2006) The Bender Gestalt II. American Journal of Orthopsychiatry. 76(1): 10-12.

2. Brannigan GG, Decker SL, Madsen DH (2004) Innovative features of the Bender-Gestalt II and expanded guidelines for the use of the Global Scoring System. (Bender Visual-Motor Gestalt Test, Second Edition Assessment Service Bulletin No.1) Itasca, IL: Riverside Publishing, USA.

3. Piotrowski C (2016) Bender Gestalt Test usage worldwide: A Review of 30 practice-based studies. Journal of Projective Psychology and Mental Health 23: 73-81.

4. Shaughnessy MF, Laman E (2012) Evidence based intervention and treatment/rehabilitation of traumatic brain injury. Research Journal in Organizational Psychology and Educational Studies 1(1): 1-12.

5. Shaughnessy MF (2018b) Neurological testing: A Contemporary Overview of Part of the Psychiatric Examination with a Focus on the Bender Gestalt II. Archives of Psychiatry and Behavioral Sciences 1(1): 48-54.

6. Brannigan GG, Decker SL (2003a) Bender Gestalt II Examiner's Manual Itasca. IL: Riverside Publishing, USA.

7. Brannigan GG, Decker SL (2003b) Bender Visual Motor Gestalt TestSecond Edition, Itasca, IL. Riverside Publishing, USA.

8. Brannigan GG, Shaughnessy MF (2013) An Interview with Gary Brannigan: Revising the Bender Gestalt Test. North American Journal of Psychology 15(2): 257-265.

9. Volker MA, Lopata C, Vujnovik RK, Smerback AM, Toomey JA, Rodgers JD, Thomeer ML (2010) Comparison of the Bender Gestalt-II and VMI-V in samples of typical children and children with high-functioning autism spectrum disorders. Journal of Psychoeducational Assessment 28: 187200.

10. Decker SL (2007) Measuring growth and decline in visual -motor processes with the Bender -Gestalt Second Edition Journal of Psychoeducational Assessment 26(1): 3-15.

11. Shaughnessy MF (2018a) The Bender Gestalt II- An Underutilized Tool in Brief Neurological Screening. Asian Journal of Research and Reports in Neurology 1(2): 1-5.

12. Shaughnessy MF (2018) The Wechsler Intelligence Scale for Adults- $\left(4^{\text {th }}\right.$ edn) and the Bender Gestalt-2: Two Revised Instruments Foundational to the Neurological Examination. EC Neurology (in press). 